REVISTA DE DERECHO UNED, NÚM. 21, 2017

\title{
JURISPRUDENCIA DE ESTRASBURGO SOBRE EL DERECHO A UN PROCESO EQUITATIVO: SENTENCIAS CONTRA ESPAÑA DE INTERÉS PARA MÉXICO
}

\author{
STRASBOURG JURISPRUDENCE ABOUT THE RIGHT \\ TO A FAIR TRIAL: JUDGMENTS AGAINST SPAIN \\ OF INTEREST FOR MEXICO
}

\author{
EdUARDo LóPEZ BETANCOURT* \\ Roberto Carlos Fonseca LuJÁN**
}

Resumen: El artículo se acerca a la jurisprudencia del Tribunal de Estrasburgo sobre el artículo 6 del Convenio Europeo (derecho a un proceso equitativo) a partir de los derechos precisados en sentencias falladas contra España. Se comentan asuntos como el derecho a un juez imparcial, los alcances extraprocesales de la presunción de inocencia, el acceso a la segunda instancia y la inmediación, el plazo razonable de duración del proceso y el acceso a la información sobre el proceso.

Abstract: This paper approaches the Strasbourg Court jurisprudence concerning Article 6 of European Convention (right to a fair trial) starting from the rights specified in judgments decided against Spain. Topics discussed are the right to an impartial judge, the extra procedural effect of presumption of innocence, the access to the se-

* Profesor de Tiempo Completo en la Facultad de Derecho de la Universidad Nacional Autónoma de México. Miembro del Sistema Nacional de Investigadores del Consejo Nacional de Ciencia y Tecnología Conacyt.

** Profesor de asignatura en la Facultad de Derecho de la Universidad Nacional Autónoma de México. 
cond instance and immediacy, the reasonable duration of trial and the access to information about prosecution.

Palabras clave: Tribunal Europeo de Derechos Humanos, proceso equitativo, debido proceso, acceso a la justicia, Artículo 6 del Convenio Europeo.

Keywords: European Court of Human Rights, fair trial, due process, access to justice, Article 6 of European Convention.

Recepción original: 04/09/2017

Aceptación original: 27/10/2017

Sumario: I. Nota introductoria. II. Precisiones conceptuales. III. El artículo 6 del Convenio Europeo. IV. Jurisprudencia y sentencias contra España. V. Comentarios conclusivos. VI. Bibliografía.

\section{NOTA INTRODUCTORIA}

El Convenio Europeo de Derechos Humanos (CEDH) denomina al derecho previsto en su artículo 6 «Derecho a un proceso equitativo». Se trata de un precepto complejo, con una gran riqueza, que dispone el contenido mínimo de los derechos de acceso a la justicia y debido proceso penal. El alcance de estos derechos se ha ido expandiendo continuamente por la interpretación que realiza el Tribunal Europeo de Derechos Humanos (TEDH) en Estrasburgo, fiel a una línea interpretativa que entiende el Convenio como un instrumento «vivo».

Los criterios desarrollados por Estrasburgo son vinculantes para los Estados europeos miembros del instrumento. Fuera de Europa, el estudio de esta jurisprudencia es relevante por un interés teórico, ya que sin duda constituye una vanguardia en el desarrollo judicial de los derechos humanos, y también por un interés práctico particularmente en Latinoamérica, puesto que muchos criterios de Estrasburgo se han visto reflejados en las decisiones de la Corte Interamericana de Derechos Humanos, en el marco del nutrido diálogo jurisprudencial entre sistemas regionales de protección de derechos humanos que se da hoy en día.

En este artículo, el acercamiento a la amplia jurisprudencia de Estrasburgo sobre el artículo 6 se delimita con base en los temas debatidos en algunas sentencias representativas falladas contra España, a partir de las cuales se trae a colación la doctrina desarrollada para otros litigios. Entre los aspectos que se comentan están los alcances extraprocesales de la presunción de inocencia, el acceso a la segunda 
instancia y la inmediación en esta, y el plazo razonable de duración del proceso. La selección de ese conjunto de fallos contra España responde a la mayor accesibilidad del material y por supuesto, a la cercanía cultural y jurídica con aquel contexto. Con independencia de eso, consideramos que en México el acceso a la justicia y el debido proceso siempre son temas urgentes cuyo abordaje, más que pertinente, es requerido.

\section{PRECISIONES CONCEPTUALES}

El Convenio Europeo de Derechos Humanos (CEDH) denomina el derecho previsto en su artículo 6 "Derecho a un proceso equitativo». Junto con esa expresión, la doctrina utiliza diversos conceptos al hablar de los derechos que involucra dicho artículo. Se habla de derechos de "acceso a la justicia», "acceso a la jurisdicción», «tutela judicial efectiva», de "audiencia» (o a ser oído), "debido proceso» (o proceso debido), «juicio justo», «juicio equitativo», "proceso garantizado por la ley», o «derecho de defensa procesal». Es necesario precisar si su alcance es el mismo o si se refieren a un contenido diferente.

Una primera distinción conceptual ${ }^{1}$ establece que las expresiones derecho de «acceso a la justicia», "acceso al proceso» $\mathrm{y}$ «tutela judicial» se refieren al derecho que tiene toda persona de acudir ante un órgano jurisdiccional para que se resuelva el litigio que plantea. En los Estados modernos, tras la proscripción de la autotutela o justicia de mano propia, todo conflicto en el cual estén en juego intereses de relevancia jurídica, debe ser resuelto por un órgano institucionalizado competente para ello. En esa medida, estos derechos al acceso a la justicia o a la tutela judicial amparan a la persona para que pueda acudir ante un órgano a exponer su causa pretendida o defender su derecho en pugna, y provocar la acción de este, es decir, que este órgano proceda a atenderle. En términos del uruguayo Marabotto Luga-

${ }^{1}$ Distinción inscrita en la exégesis generalizada del art. 24 de la Constitución Española, según la cual el primer apartado establece garantías previas al proceso, que en suma aseguran la tutela judicial efectiva o derecho de acceso a la jurisdicción; y el segundo apartado recoge las llamadas garantías procesales. Vid. RoDRíGUEz FERNÁNDEZ, R., Derechos fundamentales y garantías individuales en el proceso penal. Nociones básicas. Jurisprudencia esencial, Comares, Granada, 2000, págs. 3 y ss.; SalaH PaLACIOS, E., La tutela judicial efectiva en la jurisprudencia del Tribunal Constitucional 1981-2014, Cultiva Libros, Madrid, 2015, págs. 85 y ss.

La doctrina constitucional mexicana igualmente distingue dos ámbitos, uno del derecho de «acceso a la jurisdicción» o a la «administración de justicia» (previsto en el art. 17 de la Constitución Mexicana); y otro propiamente del derecho de «audiencia» o al «debido proceso» (previsto en el art. 14 de la Constitución Mexicana, en relación con el 20 y otros para la materia penal). 
ro, el acceso a la justicia es el «derecho de toda persona a tener un ámbito en el cual hacer valer el derecho de que se crea asistida y de lograr la satisfacción de este»².

En un segundo ámbito, las expresiones «debido proceso», «juicio justo» y "equitativo», "proceso garantizado» se entienden referidos a las características que debe tener un proceso, una vez que la controversia o la causa alegada por alguna persona ha sido admitida a juicio. Esto comprende tanto un diseño del proceso que resulte equilibrado entre las partes que intervienen, como un catálogo de derechos que deben amparar a las partes, requisitos todos para que pueda considerarse que la decisión que se dé al final será en justicia.

En este rubro, el derecho a un proceso debido o equitativo tiene como fin asegurar un enjuiciamiento justo. El juicio justo se considera «un pilar fundamental en todo orden jurídico-estatal (...) Sin la protección ante la arbitrariedad estatal y la presunción de inocencia resulta difícil crear la confianza de la opinión pública en los instrumentos jurídico-estatales en general» ${ }^{3}$. Para el Estado constitucional de derecho es fundamental el respeto a las reglas del proceso justo, que fungen como estándar contemporáneo de calidad de la justicia.

En otra acepción tradicional, la noción de «debido proceso» se restringe a las causas en las cuales lo que está en juego es una privación o limitación a derechos de la persona, como sucede típica -aunque no exclusivamente- en el proceso penal. En esta concepción, debido proceso es el conjunto de reglas básicas y derechos mínimos que deben observarse para que la privación de un derecho no resulte arbitraria. El objeto de las reglas del proceso debido es proteger a las personas de las privaciones de la vida, libertad o bienes cometidas errónea o injustificadamente. La noción se usa de forma generalizada en doctrina, aunque en el lenguaje forense del derecho internacional de los derechos humanos su uso es propio del ámbito americano, más que del europeo ${ }^{4}$.

${ }^{2}$ Marabotto Lugaro, J. A., "Un derecho humano esencial: el acceso a la justicia», Anuario de Derecho Constitucional Latinoamericano, 2003, págs. 291-301.

${ }^{3}$ Dolzer, R. y Wetzel, J., «El derecho del acusado a un juicio justo según la Convención Europea de Derechos Humanos», Anuario de Derecho Constitucional Latinoamericano, tomo II, 2006, págs. 1175-1190.

${ }^{4}$ Caballero JuÁrez, J. A., El debido proceso. Una aproximación desde la jurisprudencia latinoamericana, Suprema Corte de Justicia de la Nación, Oficina en México del Alto Comisionado de las Naciones Unidas para los Derechos Humanos, México, 2014, págs. 9-10. 
En la Convención Americana sobre Derechos Humanos o Pacto de San José, de 1969, el artículo 8, denominado «Garantías Judiciales», prevé el derecho a ser oído con las «debidas garantías». Su contenido es muy cercano al artículo $6 .^{\circ}$ del CEDH. La Convención hace mención expresa del «debido proceso legal» en el inciso a) del artículo 46.2. La jurisprudencia de la Corte Interamericana de Derechos Humanos (CIDH) utiliza el concepto «debido proceso» de forma usual, habiéndolo denominado «derecho de defensa procesal». Para la $\mathrm{CIDH}$, el debido proceso abarca las «condiciones que deben cumplirse para asegurar la adecuada defensa de aquellos cuyos derechos u obligaciones están bajo consideración judicial». De manera correlativa, exige «que las personas estén en condiciones de defender adecuadamente sus derechos ante cualquier tipo de acto del Estado que pueda afectarlos». Esto constituye un «límite infranqueable a la discrecionalidad del poder público, en cualquier materia» ${ }^{5}$.

En todo caso, las nociones están imbricadas. Las distintas denominaciones parecen atender a usos lingüísticos arraigados en las tradiciones jurídicas regionales, derivados del modo en que fue plasmada la redacción de los instrumentos jurídicos que han positivizado los derechos. Más que hablar de derechos humanos distintos, cabría hablar de un mismo derecho con distintos nombres.

\section{EL ARTÍCULO 6 DEL CONVENIO EUROPEO}

El artículo $6 .^{\circ}$ es uno de los más detallados del Convenio; en principio se observa que incluye tres párrafos, cuyo contenido es el siguiente: 1) derecho al juicio equitativo o justo ante tribunales; 2) derecho a la presunción de inocencia; 3) derechos del acusado dentro del proceso penal.

El primer párrafo prevé pautas para el derecho procesal en general, tanto en materia civil como penal. Expresa las garantías mínimas, orgánicas y procesales, del proceso justo. Se considera que en sí, no existe un concepto absoluto de proceso equitativo, sino que todas las garantías previstas en este artículo se reconducen a la noción y la dotan de contenido. Se trata de un "concepto global, integrado por una diversidad de elementos, que solo pueden concretarse atendiendo a las circunstancias particulares de cada caso». Se trata de los elemen-

${ }^{5}$ LoAyza TAMAYo, C., «El debido proceso en la jurisprudencia de la Corte Interamericana», LEX. Revista de la Facultad de Derecho y Ciencia Política de la Universidad Alas Peruanas, vol. 10, núm. 9, 2012, págs. 83-126. 
tos de «cierta idea de justicia que ha de ser aplicada a sistemas procesales a veces muy diferentes» ${ }^{6}$.

Respecto al ámbito de aplicabilidad del derecho de este primer párrafo, por la redacción parece restringirse a litigios de materia civil, entendidos como aquellos en los cuales se presentan reivindicaciones «de relevancia económica», y causas penales, según la legislación interna. Lo que se excluye, en un caso normal, son los «juicios de derecho público", por ejemplo, litigios de funcionarios sin contenido económico ${ }^{7}$. No obstante, la interpretación ha sido expansiva, superándose la redacción formal que sólo menciona procesos civiles y criminales, para reconocer su aplicabilidad en diversas índoles de órdenes jurisdiccionales; así el TEDH se ha ocupado de asuntos relacionados con el Derecho del trabajo, con el orden contencioso administrativo o la justicia militar ${ }^{8}$.

Por lo que hace a los párrafos 2 y 3 , se refieren a asuntos de carácter penal, que en conjunto son vistos como derechos complementarios del juicio justo para la materia criminal. Esto no es óbice para que algunos derechos de estos apartados se extiendan a otros ámbitos (derecho administrativo sancionador, por ejemplo) en la línea de la interpretación expansiva antes referida. Hay que distinguir el ámbito de aplicación de estos parágrafos, que es el escenario procesal, frente a los derechos que corresponden a personas privadas de la libertad del artículo 5 que establece la tutela de la libertad personal, y los derechos del artículo 7 que se reflejan en el ámbito del derecho penal sustantivo.

La titularidad del derecho de acceso del primer párrafo se entiende que es universal, según la caracterización del mismo como derecho fundamental, confirmada en la expresión «Toda persona» con la cual inicia el artículo. Así, se extiende la protección «tanto a las personas físicas como a las morales o jurídicas, así como a los extranjeros y apátridas que se encuentren bajo la jurisdicción de cualquiera de los Estados contratantes». ${ }^{9}$ No obstante lo cual, en las previsiones

${ }^{6}$ ARANGÜENA FANEGO, C., «Primera aproximación al derecho a un proceso equitativo y a las exigencias contenidas en el art. 6.1 CEDH; en particular, el derecho de acceso a un tribunal», en García RocA, F. J. (Coord.), La Europa de los Derechos. El Convenio Europeo de Derechos Humanos, 2a. ed., Centro de Estudios Políticos y Constitucionales, Madrid, 2009, págs. 259-275.

${ }^{7}$ Dolzer, R. y WeTzel, J., op. cit., pág. 1182.

${ }^{8}$ Jimena QuesadA, L., "El derecho a un proceso equitativo reconocido en el Convenio Europeo de Derechos Humanos y su proyección nacional: entre el tiempo para conocer Europa y el tiempo para hacer justicia conforme a los parámetros europeos», Cuadernos Constitucionales de la Cátedra Fadrique Furió Ceriol, núm. 50/51, 2005, pág. 186.

${ }_{9}^{9}$ Arangüena Fanego, C., op. cit., pág. 264. 
siguientes, dadas las singularidades del ámbito en que se ejerce el derecho, termina por ceñirse a quienes tienen carácter de parte en un proceso, y en el caso de los párrafos 2 y 3 a quienes tienen condición de acusados.

En el ámbito de la jurisdicción de Estrasburgo, la idea de «juicio justo» se ha entendido con un carácter global. Para decidir sobre las violaciones al artículo 6. ${ }^{\circ}$, el TEDH sigue una metodología de valoración global del asunto, para determinar si algunas limitaciones pudieron ser compensadas en otro momento. De este modo, las violaciones procesales no se traducen de forma automática en violaciones al proceso equitativo. El criterio que se sigue atiende a la suma del proceso: el reclamante señala las garantías concretas que se le incumplieron, a partir de lo cual el Tribunal realiza una ponderación general del caso para establecer si la decisión final se produjo o no en circunstancias equitativas.

\section{JURISPRUDENCIA Y SENTENCIAS CONTRA ESPAÑA}

Es indudable la relevancia que tiene la labor del Tribunal de Estrasburgo en la precisión e interpretación de los derechos humanos reconocidos en Europa, en primer lugar los previstos en el Convenio europeo, y de manera extensiva los que se establecen en las Constituciones nacionales, puesto que su jurisprudencia ejerce una fuerte influencia sobre las decisiones de los tribunales constitucionales locales que no pueden determinar el alcance y contenido de algún derecho sin atender a lo que haya precisado Estrasburgo, ya que además el Convenio constituye derecho aplicable de manera directa en el ámbito interno.

La interpretación del TEDH ha ido más allá de la literalidad del Convenio, extendiendo el alcance de los derechos fundamentales. La práctica usual es el establecimiento de los derechos «implícitos» que, según Rey Martínez, se producen de «una expansión natural del contenido de un derecho expreso por su aplicación a supuestos fácticos nuevos». En una expresión gráfica del mismo autor: «los derechos fundamentales nacen mediante dos fórmulas: o nacen por parto natural en la Constitución o por cesárea producida por la jurisprudencia constitucional». ${ }^{10}$ Cabe extender esto al ámbito del TEDH y señalar a este tribunal como un "cirujano» muy diligente.

\footnotetext{
${ }^{10}$ Rey Martínez, F., «¿Cómo Nacen los derechos? (Posibilidades y Límites de la Creación Judicial de Derechos)», en Bazán, V. (Coord.), Derecho Procesal Constitucional Americano y Europeo, Abeledo Perrot, Buenos Aires, 2010, t. II, págs. 1477-1478.
} 
En otra imagen, el TEDH tiene como premisa de su interpretación que el Convenio es un instrumento "vivo», que ha de interpretarse siempre de acuerdo a las condiciones del día actual; jamás debe ser entendido como algo «estático e inamovible». De ahí que en su interpretación teleológica, según el sentido y el fin de la Convención, el TEDH siempre ha intentado dotar a las proposiciones de la CEDH de la «mayor efectividad posible». En el mismo sentido, se menciona el "principio de la interpretación dinámica o evolutiva», de acuerdo con el cual la Convención «se encuentra sujeta a un desarrollo continuo, sobre todo en aquellos aspectos en que se comprueba un consenso progresivo de los Estados» ${ }^{11}$.

Los reclamos por violación al derecho al proceso equitativo y demás relativos del artículo 6 del Convenio ocupan buena parte del trabajo del TEDH ${ }^{12}$; de tal suerte que este derecho se perfila como uno de los centrales, incluso con carácter transversal, en tanto está en juego o puede condicionar las intervenciones públicas en la esfera de otros derechos.

El TEDH determina pautas que han de atenderse por las jurisdicciones locales europeas, pero no está destinado a sustituirlas en forma alguna ni a convertirse en última instancia en todo caso -lo que resulta equivocado en teoría e imposible en la práctica-. La adecuada difusión de sus criterios jurisprudenciales es imprescindible para que los tribunales nacionales puedan aplicarlos directamente, evitando violaciones a derechos, y así detener la situación que se vive, en la cual los justiciables en el ámbito interno, asumen de manera errónea que el TEDH es "otra instancia», a la cual se puede acudir en todo caso, cuando la justicia nacional no les da la razón. Para el caso de España, según comenta Quesada Jimena: «la institución del Tribunal de Estrasburgo como remedio último y subsidiario es concebida finalmente como una instancia judicial más en la que se depositan las últimas expectativas, tal vez con demasiado optimismo [Se observa que] la configuración del Tribunal Europeo como una instancia excepcional ha devenido una "moda" ${ }^{13}$.

Fuera de Europa, el estudio de su jurisprudencia es relevante, dado el nutrido diálogo que se da entre sistemas regionales de protección de derechos humanos, particularmente entre el TEDH y la CIDH. En este entendido, a continuación se presenta un panorama de

${ }^{11}$ Dolzer, R. y Wetzel, J., op. cit., pág. 1177.

${ }^{12}$ En el buscador de jurisprudencia del TEDH (http://hudoc.echr.coe.int/) de los más de 40,000 asuntos indexados, 26,000 se refieren al art. 6. ${ }^{\circ}$ del Convenio.

${ }^{13}$ Jimena Quesada, L., op. cit., pág. 178. 
algunos temas relevantes que han sido precisados por el TEDH sobre el contenido del artículo 6, a partir de las principales sentencias pronunciadas contra España por violaciones al mismo precepto ${ }^{14}$.

\section{Violación al principio de inmediación en segunda instancia}

La inmediación se ha considerado una garantía fundamental del derecho a ser oído equitativamente. Lo "equitativo» se refiere al derecho a la igualdad de armas y al carácter contradictorio del procedimiento. La igualdad de armas es la expresión del principio general de igualdad en el ámbito procesal, e implica que se den a ambas partes iguales oportunidades de exponer y probar su pretensión, así como de alegar en favor de esta, sin que se den ventajas a ninguna de ellas. Aunque esta "igualdad de armas» no se expresa textualmente en el Convenio, se desprende del carácter balanceado del mismo.

La igualdad de armas conlleva el respeto del principio contradictorio, que implica, tanto para la acusación como para la defensa, la facultad de tomar conocimiento de las observaciones y elementos de prueba presentados por la otra parte, y de poder dar una respuesta ${ }^{15}$. Con precisión: «El derecho a un procedimiento contradictorio implica, para una parte, la facultad de conocer las alegaciones o documentos presentados por la otra, así como de discutirlas» ${ }^{16}$.

El derecho a ser «oído» de forma equitativa se ha considerado violado en segunda instancia, cuando habiendo necesidad de efectuar una vista pública, esta no se lleva a cabo. Evidentemente, no puede haber una segunda vista oral en todo recurso, pues eso convertiría lo que es precisamente un recurso, en un segundo juicio. La necesidad de realizar esa «segunda» vista ha de estar claramente delimitada; en los casos resueltos por el TEDH se ha concretado a los escenarios en los cuales el tribunal de apelación requiere hacer examen de los hechos en controversia, y no sólo dar una reinterpretación jurídica a los mismos.

${ }^{14}$ Las sentencias contra España se consultaron directamente. El resto de los criterios del TEDH mencionados se desprenden de sentencias citadas en: CASADEVALL, J., El Convenio Europeo de Derechos Humanos, el Tribunal de Estrasburgo y su Jurisprudencia, Tirant lo blanch, Valencia, 2012, págs. 263-315; VV. AA., Convenio Europeo de Derechos Humanos. Comentario sistemático, 2a ed., Civitas, Thomson Reuters, Pamplona, 2009, págs. 172-253.

15 TEDH, Sentencia Belziuk c. Polonia, 25 de marzo de 1998.

16 TEDH, Sentencia Ruiz Mateos c. España, 23 de junio de 1993. 
En estas sentencias, el derecho a un proceso equitativo se ha considerado violado por incumplimiento del principio de inmediación, cuando un tribunal de segunda instancia modifica la resolución de primera instancia, con base en una reapreciación del material probatorio, sin haber presenciado ningún desahogo de prueba, sólo a partir de los documentos del expediente.

\section{A. Sentencia Lacadena Calero c. España, 22 de noviembre de 2011}

El TEDH consideró violatorio del derecho que el Tribunal de casación hubiera realizado una nueva valoración de la culpabilidad con base en la distinta apreciación de un elemento subjetivo (dolo eventual), pero sin realizar la valoración directa del testimonio del acusado o incluso del de otros testigos. En la vista celebrada, el acusado no fue oído personalmente sobre esa cuestión determinante, por lo cual fue privado de su derecho a defenderse en el marco de un debate contradictorio (párrs. 49-51).

En los principios aplicados a esta Sentencia (párrs. 36-38), el TEDH establece que después de celebrado un juicio en primera instancia, la ausencia de una vista en sede de apelación o casación puede justificarse por las particularidades del procedimiento en cuestión: el sistema interno, los poderes de la jurisdicción de segunda instancia, y la naturaleza de las cuestiones que deben ser resueltas. Los procedimientos de apelación dedicados exclusivamente a puntos de derecho y no de hecho pueden cumplir con el art. 6 del CEDH aun si el Tribunal de apelación o de casación no otorga al recurrente la facultad de expresarse en persona ante él. Esto, porque no le incumbe a esta jurisdicción establecer los hechos, sino únicamente interpretar las razones jurídicas aplicables. No obstante, cuando una instancia de apelación conoce tanto las cuestiones de hecho como de derecho del asunto, y estudia en su conjunto la cuestión de la culpabilidad o inocencia, no puede, por motivos de equidad del proceso, decidir en omisión de una valoración directa de los medios de prueba. En casos así, la revisión de la culpabilidad exige una nueva audiencia integral con las partes interesadas ${ }^{17}$.

${ }^{17}$ Precedentes relacionados y citados en el caso: Sentencia Botten c. Noruega, 19 de febrero de 1996; Sentencia Monnell y Morris c. Reino Unido, 2 de marzo de 1987; Sentencia Sutter c. Suiza, 22 de febrero de 1984; Sentencia Ekbatani c. Suecia, 26 de mayo de 1988; Sentencia Igual Coll c. España, 10 de marzo de 2009; Sentencia Marcos Barrios c. España, 21 de septiembre de 2010; Sentencia García Hernández c. España, 16 de noviembre de 2010; Sentencia Dondarini c. San Marino, 6 de julio de 2004; Sentencia Constantinescu c. Rumania, 27 de junio de 2000. 
B. Sentencia Valbuena Redondo c. España, 13 de diciembre de 2011.

El Tribunal considera que al depender la decisión del órgano de alzada de una nueva apreciación de las cuestiones fácticas, el cambio en la valoración de elementos subjetivos referidos al probable responsable sin un examen directo de este, "sin que este hubiese tenido la oportunidad de ser oído personalmente y de discutirlos mediante un examen contradictorio en el curso de una vista oral, no es conforme con las exigencias de un proceso equitativo». La extensión del examen efectuado en el caso hacía necesaria una vista oral ante la jurisdicción de apelación, que al no presentarse, actualizó la violación al CEDH (párrs. 37-40).

En las Sentencias Serrano Contreras c. España, 20 de marzo de 2012; Vilanova Goterris y Llop García c. España, 27 de noviembre de 2012; Román Zurdo y otros c. España, 8 de octubre de 2013; Nieto Macero c. España, 8 de octubre de 2013; Sainz Casla c. España, 12 de noviembre de 2013; el TEDH encontró igualmente una violación al derecho del 6.1 $\mathrm{CEDH}$ en circunstancias similares a las de los casos Lacadena Calero y Valbuena Redondo, y con aplicación de razonamientos de derecho análogos. Este amplio grupo de fallos revelan lo que había sido una violación recurrente en el ámbito de la segunda instancia, debida a una visión procesal tradicional -ya superada- según la cual no era requerida la vista oral en la alzada, precisamente para no repetir el juicio.

\section{Violación a un proceso en un plazo razonable}

El derecho a que la resolución se dé en un plazo razonable se entiende como el derecho a un proceso sin dilaciones indebidas. Los reclamos por justicia retardada son habituales; al respecto, hay que considerar que la lentitud de la justicia es un problema crónico de las sociedades contemporáneas, en el cual inciden multiplicidad de factores, entre esos la carga de trabajo. El propio TEDH está sobresaturado, debido a que recibe miles de demandas al año; tan sólo la determinación de la admisión de la demanda en la instancia supranacional puede demorar unos años. De manera un tanto trágica, se afirma que los juicios ante el TEDH «demoran tanto que ya se puede volver a considerar una infracción al derecho a una duración adecuada del juicio» ${ }^{18}$.

${ }^{18}$ Dolzer, R. y Wetzel, J., op. cit., pág. 1189. 
La idea de "plazo razonable» no supone un período determinado; se ha de apreciar en cada caso concreto. Entre los factores a considerar para dotar de contenido a esa idea de duración razonable, se toma en cuenta la complejidad del caso desde una perspectiva global, que abarca cuestiones como el número de instancias judiciales o administrativas que han intervenido en el procedimiento, el tiempo invertido en cada una, la conveniencia de celebrar una o más audiencias, el asunto sometido a litigio, el número de partes o encausados, la dificultad para practicar pruebas como interrogación de testigos y práctica de periciales, y la tramitación de comisiones rogatorias ${ }^{19}$.

Otro factor que se considera es el comportamiento de la parte demandada, lo cual implica que no ha de ser el propio reclamante quien motivó las dilaciones con sus omisiones procesales. Si se encuentra que la duración del procedimiento fue consecuencia de peticiones de aplazamiento de trámites procesales o de retrasos en la presentación de documentos por los litigantes, particularmente de la parte demandante, el TEDH considera que la prolongación del proceso deja de ser atribuible al Estado ${ }^{20}$.

Normalmente, constituyen violación a este derecho las dilaciones que son responsabilidad directa de los órganos estatales. En los siguientes asuntos, los retrasos de siete, once y hasta trece años en concluir los procesos en cuestión en estas demandas se hallaron visiblemente fuera de todo plazo razonable.

A. Sentencia Bendayan Azcantot y Benalal Bendayan c. España, 9 de junio de 2009

En este asunto, el TEDH encontró que hubo violación al derecho a un proceso resuelto en un plazo razonable, toda vez que la causa reclamada por los demandantes, en concreto la ejecución de la sentencia penal firme desde 1997, en rubros de responsabilidad civil emanada del delito y gastos y costas, no había sido ejecutada más de siete años después. Aunque el caso revestía cierta complejidad, la decisión estimó que «las autoridades competentes habrían debido actuar con más diligencia con el fin de no causar perjuicio a las posibi-

${ }^{19}$ TEDH, Sentencia Diaz Aparicio c. España, 11 de octubre de 2001; Sentencia Becker c. Alemania, 26 de septiembre de 2002; Sentencia Pélissier et Sassi c. Francia, 25 de marzo de 1999; Sentencia Wejrup c. Dinamarca, 7 de marzo de 2002.

${ }^{20}$ TEDH, Sentencia Georgiades c. Chipre, 24 de septiembre de 2002. 
lidades efectivas de ejecución de la sentencia dictada en cuanto a lo principal y para no favorecer al deudor y su familia» (párr. 72).

En este caso, revisando los precedentes, el TEDH señala que la duración del proceso, en un «plazo razonable» se aprecia según las circunstancias del caso, en atención a los siguientes criterios: «la complejidad del asunto, el comportamiento del demandante y el de las autoridades competentes así como la importancia del litigio para los interesados» (párr. 69).

En un voto particular, los jueces disidentes consideran que la vulneración al art. 6.1 del Convenio no se dio por la duración de un procedimiento fuera de plazo razonable, sino por la no ejecución de la sentencia. El Estado falló en sus obligaciones relativas, cuando en el caso "se trataba de ejecutar una sentencia que imponía una obligación de pago a unos particulares. A este respecto, el Estado debería haber puesto a disposición del demandante un sistema que le permitiera obtener del deudor, el pago de las sumas concedidas por las jurisdicciones» (párr. 4, voto particular).

\section{B. Sentencia Moreno Carmena c. España, 9 de junio de 2009}

En este caso, se encontró una violación al derecho a la resolución del proceso en un plazo razonable, dado que el proceso penal contra la persona reclamante, desde el momento en que se abrió hasta la decisión final de sobreseimiento, había durado trece años y casi seis meses. Lo inusitado de este período no requería mayor argumentación. En general, el TEDH reafirma que: «incumbe a los Estados contratantes organizar su sistema judicial de manera que sus jurisdicciones puedan cumplir cada una de sus exigencias, incluida la obligación de resolver las causas en plazos razonables» (párr. 55).

\section{Sentencia Ortuño Ortuño c. España, 27 de septiembre de 2011}

Se decidió en este caso por el TEDH la existencia de una violación al art. 6.1 del Convenio, derecho a la resolución del procedimiento en un plazo razonable, debido a la duración de más de once años sin resolver de un procedimiento de ejecución de sentencia definitiva que ordenaba la liquidación del régimen económico matrimonial. La argumentación reitera los puntos principales mencionados en los dos casos citados antes. 
D. Sentencia Serrano Contreras c. España, 20 de marzo de 2012.

Además de la violación al derecho a ser oído y a la inmediación en la segunda instancia, el TEDH considera que en este asunto se actualizó una violación al derecho a un proceso en un plazo razonable. El proceso penal en este caso había durado más de once años. Respecto a la muy usual justificación alegada por las autoridades de «sobrecarga de trabajo», el TEDH apunta que «el atasco crónico en los asuntos atribuidos a un tribunal no es una explicación válida». Asimismo, se admiten «las dificultades que retrasan a veces el examen de los litigios de los que conocen los órganos jurisdiccionales nacionales y que resultan de distintos factores». En ese contexto, se «reitera que únicamente las dilaciones imputables al Estado pueden conducir a la declaración de que se haya sobrepasado un plazo razonable» (párrs. 57-58).

\section{Violación al acceso a la jurisdicción de recurso}

El derecho de acceso a la jurisdicción se configura como la prerrogativa de acudir ante el tribunal establecido. El artículo 6 no recoge expresamente un derecho de acceso a la segunda instancia; este fue establecido en el 7. ${ }^{\circ}$ Protocolo Adicional.

El derecho de acceso puede admitir restricciones acordes a la legislación interna, siempre que las mismas resulten proporcionadas y legítimas. En general, las limitaciones no deben restringir el acceso a la justicia del individuo hasta el punto de afectarlo de modo sustancial. Debe haber una relación de proporcionalidad, entre los medios de restricción empleados y el fin que se pretende conseguir. En esos casos, la ponderación se da entre dicho derecho y la pretensión legítima de asegurar el respeto a las condiciones formales para acudir ante una jurisdicción ${ }^{21}$.

A. Sentencia Sociedad Anónima del Ucieza c. España, 4 de noviembre de 2014

El TEDH decide en este caso la violación al art 6.1 del Convenio por la no admisión de un recurso de casación, debido a una interpretación particularmente rigurosa de la norma procedimental de admi-

${ }^{21}$ TEDH, Sentencia Kadlec c. República Checa, 25 de mayo de 2004. 
sión, lo que se tradujo en una privación del derecho a la tutela judicial efectiva.

Sobre los requisitos de admisibilidad de los recursos, el TEDH señala que «la normativa relativa a las formalidades y plazos a cumplir para interponer un recurso tiene como objetivo asegurar una buena administración de la justicia y el respeto, en particular, de la seguridad jurídica». Se entiende que el «derecho a un tribunal», particularmente en caso de recursos, "no es absoluto y se presta a unas limitaciones implícitamente admitidas, en lo que especialmente se refiere a las condiciones de admisibilidad de un recurso», siendo cuestión de derecho interno el establecimiento de esas condiciones. Se precisa que esas limitaciones «no podrían restringir el acceso de un justiciable, de manera o a un punto tal que su derecho a la tutela judicial fuera vulnerado en su propia esencia». Sólo se consideran compatibles con el Convenio "si tienden a un objetivo legítimo y si existe una relación razonable de proporcionalidad entre los medios empleados y el fin que se persigue» (párrs. 34-35).

\section{Violación al derecho a un juez imparcial}

El párrafo primero del artículo 6 contiene el derecho a un Tribunal independiente, imparcial y establecido por ley. Se ha considerado que estas garantías se vinculan intrínsecamente con la definición de lo que es un juez: un juez groseramente parcial, deja de ser un juez. En su conjunto, estas garantías orgánicas conforman el estándar de lo que se viene denominando derecho a la «buena administración de justicia».

La garantía recoge el derecho al juez natural u ordinario, que es el derecho a acceder a un tribunal de competencia general establecido previamente por la ley, con anterioridad al hecho que será puesto a su consideración. Esto lleva a rechazar los jueces especiales, excepcionales o ad hoc, así como los que se orquestan de facto. Esta garantía refleja un principio fundamental del Estado de Derecho, puesto que un órgano no establecido de conformidad con la voluntad del legislador carecería de la legitimidad requerida en cualquier sociedad democrática para conocer y resolver los litigios entre particulares. No sólo se requiere base legal en cuanto a la existencia del tribunal, sino también a la composición de la instancia en cada caso concreto ${ }^{22}$.

${ }^{22}$ TEDH, Sentencia Lavents c. Letonia, 28 de noviembre de 2002. 
Un «tribunal» se define en forma extensiva, como todo órgano que «se caracteriza, en el sentido material del término, por su función jurisdiccional: resolver, conforme a las reglas del Derecho y después de un procedimiento reglado, cualquier cuestión que dependa de su competencia». Entre sus requisitos mínimos están los ya mencionados de independencia, especialmente en relación al Poder Ejecutivo, imparcialidad, inamovilidad, garantías de procedimiento ${ }^{23}$.

Sobre el defecto de parcialidad, se ha precisado que en buena medida depende de la imagen que proyecte el tribunal. Se da gran importancia a las apariencias para valorar la imparcialidad, puesto que «lo que está en juego es la confianza que los tribunales deben inspirar a los ciudadanos en una sociedad democrática ${ }^{24}$. Es decir, el tribunal no sólo en su comportamiento debe abstenerse de realizar ninguna acción que le haga perder la confianza de las partes y de la sociedad; también su diseño estructural debe dejar claro que está garantizada su imparcialidad. Cualquier vicio en la dimensión subjetiva u objetiva que desacredite esa imagen de imparcialidad, puede conducir a que se estime violentada la garantía, aun sin necesidad de que ese órgano haya dictado resolución alguna.

La independencia se aprecia como un requisito de la imparcialidad, que atañe al conjunto del Poder Judicial frente a otros poderes del Estado, principalmente el Ejecutivo. Esa distancia debe darse tanto en el plano formal como material. Ciertas circunstancias objetivas -como la forma de designar a los miembros de un Tribunal- pueden levantar una sospecha de dependencia, pero esto se desvanece si se prevén reglas de abstención y recusación que garanticen la independencia del órgano. La estabilidad del funcionario judicial, vinculada a la duración de su mandato, también resulta un criterio relevante para analizar su independencia; aunque no hay un período mínimo que se considere necesario ${ }^{25}$.

La violación a este derecho puede presentarse también por otra clase de circunstancias procesales; por ejemplo, cuando el órgano judicial encargado de juicio, se ha "contaminado» formulando una opinión previa del asunto, al intervenir tomando decisiones en el mismo en la etapa de instrucción. En los casos que se refieren, se considera en duda la imparcialidad objetiva del tribunal de juicio por la

${ }^{23}$ TEDH, Sentencia Belilos c. Suiza, 29 de abril de 1988.

24 TEDH, Sentencia Piersack c. Bélgica, 1 de octubre de 1982.

25 TEDH, Sentencia Belilos c. Suiza, 29 de abril de 1988; Sentencia Campbell c. Reino Unido, 28 de junio de 1984; Sentencia Findlay c. Reino Unido, 25 de febrero de 1997. 
participación previa del magistrado en la decisión sobre la prisión provisional del procesado, acto que no consiste simplemente en un conocimiento somero del asunto, sino que implica una opinión sobre la eventual responsabilidad de la persona.

\section{A. Sentencia Cardona Serrat c. España, 26 de octubre de 2010}

En este asunto, el TEDH encontró que se había vulnerado en perjuicio de la persona demandante el derecho a un juez imparcial, toda vez que el órgano judicial encargado de juzgarlo y condenarlo, tuvo conocimiento previo del asunto en la etapa de instrucción, realizando actos como era ordenar la prisión provisional, por lo cual antes del juicio era probable que ya se hubieran formado una opinión sobre su probable responsabilidad, lo que implicaba una pérdida de imparcialidad. Cabe precisar que el TEDH no consideró probado que los magistrados hubieran mostrado una parcialidad subjetiva, pero sí consideró que, en las circunstancias del caso, las dudas del demandante sobre la imparcialidad objetiva del órgano judicial podían considerarse justificadas, y en consecuencia, debió admitirse la recusación ${ }^{26}$.

En esta sentencia, el TEDH revisa su doctrina que perfila dos dimensiones de la imparcialidad judicial: subjetiva y objetiva. La primera se refiere a la persona de los magistrados, y sobre la misma existe una "presunción», que admite prueba suficiente en contrario. De todas formas, el Tribunal recuerda «que en los casos donde puede ser difícil proporcionar pruebas que permitan refutar la presunción de imparcialidad subjetiva del juez, la condición de imparcialidad objetiva proporciona una importante garantía suplementaria» (párr. 29).

B. Sentencia Alony Kate c. España, 17 de enero de 2012

En una situación similar a la sentencia anterior, una de las magistradas que dictó la sentencia condenatoria de la persona reclamante había participado previamente dictando la orden de prisión provisional en su contra, así como la resolución que confirmó dicha orden. En consecuencia, el TEDH consideró que de en las circunstancias del caso, las dudas del demandante sobre la imparcialidad objetiva del órgano judicial podían considerarse justificadas.

${ }^{26}$ Precedentes citados en el caso: Sentencia Pullar c. Reino Unido, 10 de junio de 1996. 
En este asunto también se debate sobre la ilicitud de pruebas derivadas de una intervención de comunicaciones, respecto a las cuales el TEDH considera finalmente que no se presentó la violación a derechos del Convenio.

\section{Violación a la presunción de inocencia en el ámbito de las consecuencias extraprocesales}

De acuerdo con el Convenio sólo la declaración legal de culpabilidad destruye la presunción de inocencia. Así, como garantía dentro del proceso, la presunción supone el deber de probar lícita y suficientemente esa culpabilidad.

La principal consecuencia de la presunción de inocencia es que la carga de la prueba recae sobre el órgano de acusación, y la duda beneficia a la persona acusada ${ }^{27}$. La presunción abarca todo el procedimiento; no se limita al examen de fondo de la acusación. Asimismo, se extiende a todos los actores institucionales. Por lo que hace al renglón de la resolución, ni el juez ni el tribunal pueden partir para el juicio de una idea preconcebida sobre la autoría de la persona imputada.

Lo anterior no impide que el acusado pueda probar su inocencia con cierta inversión de la carga de prueba, siempre que la masa de elementos de inculpación corresponda al acusador. En sentido similar, no se considera de antemano que las presunciones previstas en la ley penal contra el acusado sean incompatibles con el convenio, siempre que resulten ajustadas a límites razonables, según el asunto y la necesidad de salvaguardar los derechos de la defensa ${ }^{28}$.

Los derechos a no declararse culpable, a la no auto-incriminación, y a guardar silencio no se señalan expresamente en el Convenio, pero se han considerado implícitamente contenidos en el derecho a la presunción de inocencia. Estos derechos se sustentan en la protección que se da al acusado frente a coerciones abusivas de parte de las autoridades, dirigidas además a evitar los errores judiciales, pues las declaraciones por la fuerza carecen de fiabilidad.

El derecho a no contribuir con la propia incriminación presupone que la acusación debe abstenerse de recurrir a elementos probatorios obtenidos contra la voluntad del acusado. No obstante, cabe que las autoridades tomen en cuenta para el proceso datos o informaciones

${ }^{27}$ TEDH, Sentencia Barberá, Messegué y Jabardo c. España, 6 de diciembre de 1998.

${ }^{28}$ TEDH, Sentencia Salabiaku c. Francia, 7 de octubre de 1998. 
obtenidos con independencia de la voluntad del sospechoso, mediante orden judicial, como resultados de exámenes clínicos o pruebas de ADN derivados de muestras biológicas de sangre, orina o tejidos ${ }^{29}$.

Respecto al derecho a guardar silencio, el TEDH considera que no es absoluto, y que si bien por una parte no es posible fundamentar una condena exclusivamente en el silencio de una persona o en su negativa a declarar, por otro lado no se puede impedir que el juez extraiga conclusiones de ese silencio, cuando la actitud adoptada por el acusado es negativa, en situaciones en las cuales se requiere de manera manifiesta una explicación de su parte para apreciar debidamente los hechos y los elementos de cargo ${ }^{30}$.

Adicionalmente, el TEDH ha establecido que la presunción de inocencia exige un tratamiento digno para el procesado, que no puede ser considerado culpable en ninguna esfera y por ninguna autoridad, hasta que se resuelva en sentencia. Precisamente respecto a esos alcances fuera del proceso, se considera que ningún representante del Estado puede manifestar, ni dar a entender, que una persona es culpable de una infracción penal antes de que su responsabilidad sea declarada por el tribunal. Asimismo, que una vez decretada una sentencia absolutoria, resulta violatorio del derecho expresar «sospechas sobre la inocencia» de la persona que ya fue absuelta.

\section{A. Sentencia Tendam c. España, 13 de julio de 2010}

En este caso, el TEDH encontró que se había vulnerado el derecho a la presunción de inocencia del reclamante en una sede posterior al proceso penal, dado que tras haber sido absuelto, la persona había solicitado la indemnización por la prisión provisional padecida y esta se le había negado porque en la causa penal no se había acreditado la inexistencia de los hechos y en consecuencia su inocencia, sino que la decisión se había dado por falta de pruebas. El TEDH consideró que esta decisión implicaba expresar «sospechas sobre la inocencia» de la persona tras una absolución, y en consecuencia, se vulneraba efectivamente la presunción de inocencia. A juicio del TEDH, la distinción «entre una absolución por falta de pruebas y una absolución resultante de la comprobación de la inexistencia de hechos delictivos, ignora la previa absolución del acusado, cuya disposición debe ser respetada por todas las autoridades judiciales, cualquiera que sean las razones dadas por el juez» (párr. 16).

${ }^{29}$ TEDH, Sentencia Saunders c. Reino Unido, 17 de diciembre de 1996.

${ }^{30}$ TEDH, Sentencia John Murray c. Reino Unido, 8 de febrero de 1996. 
En este caso, el TEDH recuerda que este derecho se vulnera no sólo en caso de sentencia condenatoria, sino en todo caso que «una decisión judicial concerniente a un procesado refleja el sentimiento de que es culpable, cuando su culpabilidad no haya sido legalmente establecida con anterioridad. Basta, incluso en ausencia de declaración formal, un razonamiento sugiriendo que el juez considere a los interesados como culpables» (párr. 12).

Esto puede incluir la expresión de «sospechas sobre la inocencia», en el caso en que un proceso penal haya concluido con una sentencia absolutoria, supuestos en los cuales la presunción de inocencia se extiende a todo procedimiento consecutivo: «una vez la absolución sea definitiva -incluso si se trata de una absolución en beneficio de duda (...) la expresión de duda sobre la culpabilidad, incluidas las derivadas de los motivos de la absolución, no son compatibles con la presunción de inocencia» (párr. 13).

Complementariamente, se apunta que en virtud del principio in dubio pro reo, "no debe existir ninguna diferencia cualitativa entre una liberación por falta de pruebas y una liberación resultante de una constatación de inocencia de la persona que no está en duda», dado que «las sentencias de absolución no se diferencian en función de los motivos dictados por el juez» (párr. 14).

\section{B. Sentencia Lisazo Azconobieta c. España, 28 de junio de 2011}

El TEDH encontró violación al derecho a la presunción de inocencia porque la persona reclamante, tras su detención, fue presentada en una rueda de prensa al público y medios de comunicación como miembro de una banda terrorista, siendo identificada como responsable de delitos de manera infundada y apresurada, sin haber sido aún puesto a disposición del Juez.

En este caso, el TEDH tiene oportunidad de revisar su jurisprudencia anterior sobre la presunción de inocencia y su alcance, que no se limita a ser una simple garantía del proceso penal. Según recuerda el TEDH, este alcance «es más amplio y exige que ningún representante del Estado o de la autoridad pública declare que una persona es culpable de una infracción antes de que su culpabilidad haya sido establecida por un tribunal». En consecuencia, una violación "puede emanar no sólo de un Juez o de un tribunal sino también de otros agentes del Estado y personalidades públicas» (párrs. 37-38). 
Ya en terrenos de la libertad de información, la aparente oposición entre la presunción de inocencia y la información al público de parte de las autoridades de las investigaciones penales, se resuelve cuando dicha información se efectúa "con toda la discreción y la reserva que impone el principio», de modo que la comunicación que se haga, esté exenta «de cualquier apreciación o prejuicio de culpabilidad». Para esto, debe hacerse una "distinción entre las declaraciones que reflejan el sentimiento de que la persona afectada es culpable y las que se limitan a describir un estado de sospecha» (párr. 39). Evidentemente, son las primeras las que vulneran la presunción de inocencia. Aquí, sin entrar en ese otro tema, lo que se busca evitar son los llamados «juicios paralelos» o mediáticos.

\section{Violación al derecho dentro del proceso penal a ser informado de la acusación}

El párrafo $3 .^{\circ}$ del artículo 6 incluye un listado de los mínimos que en el ámbito del proceso penal particularizan el derecho a un proceso equitativo. La primera garantía es el derecho a conocer la acusación, generalmente llamado derecho a la información. Este derecho a la información sienta la posibilidad del derecho de defensa, pues a partir del conocimiento del cargo, la persona estará en posibilidades de prever frente a qué alegaciones deberá responder. Esto ha de incluir los hechos imputados en sentido material, así como la calificación jurídica que la autoridad proponga, de manera precisa y completa.

En la práctica, de acuerdo con los reclamos generales sobre el rubro planteados ante el TEDH, los problemas suelen ser la falta de debida y suficiente notificación de los motivos de incriminación, el hecho de no facilitar la traducción en una lengua que la persona comprenda, y las recalificaciones de la acusación a lo largo del procedimiento no informadas con oportunidad al procesado ${ }^{31}$.

\section{A. Sentencia Varela Geiis c. España, 5 de marzo de 2013}

En este asunto, el TEDH encontró una violación a las garantías del acusado, concretamente del dispositivo que precisa su derecho ser informado de manera detallada, de la naturaleza y de la causa de la

${ }^{31}$ TEDH, Sentencia Kamasinski c. Austria, 19 de diciembre de 1989; Sentencia Bozicek c. Italia, 19 de diciembre de 1989; Sentencia Sadak y otros c. Turquía, 17 de julio de 2001. 
acusación formulada contra él, con la consecuencia de violación del derecho a preparación de la defensa. Dicha violación se presentó porque durante el proceso hubo una modificación relevante de la calificación jurídica, de modo que la hipótesis delictiva por la cual finalmente se condenó en apelación era diversa de la que había figurado en el escrito de acusación y en primera instancia. El órgano de apelación hizo una recalificación de los hechos de «negación» en «justificación» del genocidio, sin que se hubiera informado oportunamente de esto a la persona sujeta a proceso, con lo cual, se conculcó su derecho a preparar su defensa sobre ese punto concreto.

En esta sentencia, el TEDH menciona su jurisprudencia anterior sobre el derecho a ser informado de la acusación, inciso a) del art. 6.3. Se señala que estas disposiciones «muestran la necesidad de cuidar en extremo la notificación al interesado de la causa de la «acusación» formulada en su contra». Esto es así porque el escrito de acusación «juega un papel determinante en las diligencias judiciales: a partir de su notificación, la persona encausada está oficialmente informada de la base jurídica y factual de los reproches formulados en su contra». El alcance del derecho incluye la información de los hechos imputados que fundamentan la acusación, y también «de la tipificación jurídica con la que se califica estos hechos, y esto, de una forma detallada». Esto se relaciona directamente con el proceso equitativo; el TEDH «considera que, en materia penal, una información precisa y completa de los cargos que pesan contra un acusado, y por tanto la tipificación jurídica que la jurisdicción pueda tomar en consideración en su contra, es una condición esencial de la equidad del procedimiento». En complemento, este derecho a la información resulta imprescindible para el derecho de defensa: «existe un vínculo entre los apartados a) y b) del artículo $6 \S 3$ y que el derecho a ser informado de la naturaleza y la causa de la acusación debe ser contemplado a la luz del derecho para el acusado de preparar su defensa» (párrs. 41-44) ${ }^{32}$.

Sobre este derecho del inciso b) del párrafo 3 del convenio cabe abundar que no se trata del derecho a la defensa en sentido estricto, sino de la oportunidad de "prepararla», es decir, tener la posibilidad, tanto en tiempo como en facilidades de acceso a las fuentes de información que requiera, para reunir los elementos para tal propósito. En el caso en que se vaya a dar una defensa por letrado, el derecho supo-

${ }^{32}$ Precedentes relacionados y citados en el caso: Sentencia Kamasinski c. Austria, 19 de diciembre de 1989; Sentencia Pélissier y Sassi c. Francia, 1999-II; Sentencia Artico c. Italia, 13 de mayo de 1980; Sentencia Colozza c. Italia, 12 de febrero de 1985. 
ne también que el abogado tenga tiempo y oportunidad suficientes y razonables para enterarse del caso y disponer la estrategia procesal.

Las facilidades para preparar la defensa se traducen en el ya comentado derecho a la información, en la dimensión de poder tener acceso al expediente, y a la asistencia letrada. El derecho no supone el acceso "directo» o personal del acusado al sumario, sino que puede darse por medio de abogado, cuando el acusado está representado por dicho defensor. No obstante, si la persona acusada decide defenderse por sí misma, y la legislación interna no impone la asistencia letrada, entonces el propio acusado tiene derecho a obtener el conocimiento completo de todas las actuaciones contenidas en el sumario ${ }^{33}$.

El derecho supone igualmente una dimensión temporal, de modo que tras determinaciones judiciales de relevancia como una recalificación jurídica, ha de darse oportunidad adecuada para replantear la defensa. De este modo, si el Tribunal recalifica los hechos, debe dar a la persona procesada tiempo suficiente, incluso aplazar la vista pública para que el acusado reorganice su línea de defensa en función de la nueva calificación ${ }^{34}$. Lo mismo si la variación se presenta durante el curso de la audiencia, por ejemplo, en lo relativo a la versión de los hechos y el sustento de la acusación, por el resultado de los testimonios, la persona acusada ha de tener posibilidad de reaccionar en su defensa y disponer de tiempo necesario incluso para ofrecer nuevas pruebas $^{35}$.

\section{COMENTARIOS CONCLUSIVOS}

El concepto de proceso equitativo es poco utilizado en la doctrina constitucional mexicana, que se ha desarrollado sobre conceptos como los de garantía de audiencia, formalidades esenciales del procedimiento, y debido proceso legal. No obstante, más allá de las distintas denominaciones que se puedan dar a estos derechos, lo que recogen es un ideal compartido, de un modelo procesal que resulte respetuoso con la dignidad humana.

El derecho al proceso equitativo que consagra el artículo $6 .^{\circ}$ del Convenio Europeo de Derechos Humanos, junto con los múltiples sub derechos que ha derivado del texto la jurisprudencia del Tribunal de Estrasburgo, se han consolidado como un aspecto central en el siste-

\footnotetext{
${ }^{33}$ TEDH, Sentencia Foucher c. Francia, 18 de marzo de 1997.

${ }^{34}$ TEDH, Sentencia Sadak y otros c. Turquía, 17 de julio de 2001.

35 TEDH, Sentencia Mattoccia c. Italia, 25 de julio de 2000.
} 
ma europeo de derechos humanos, e igualmente como un pilar en la estructura y el funcionamiento de los Estados en el horizonte de las sociedades democráticas actuales. El Convenio es evidentemente un modelo perfectible, pero sin duda se consolida como un gran avance histórico.

La aplicación del precepto y su jurisprudencia es un deber en el ámbito interno de los Estados europeos, de modo que su conocimiento se revela imprescindible para los operadores jurídicos de aquella región. Para el contexto latinoamericano, según se ha sugerido, el estudio del Convenio Europeo resulta útil para una mejor comprensión en el análisis de su disposición hermana, el artículo $8 .^{\circ}$ de la Convención Americana sobre Derechos Humanos, respecto al cual se ha producido igualmente una nutrida jurisprudencia por la jurisdicción internacional correspondiente, esta sí vinculante para las naciones de la región, como es México.

Particularmente en México, ahora que se vive el tránsito hacia el modelo de justicia penal acusatorio y oral, es fundamental el conocimiento de las soluciones que se han gestado en otras latitudes, así como la doctrina de vanguardia sobre derechos humanos que deben regir en el proceso penal para que este resulte justo y legítimo en nuestras sociedades, superando los rezagos en ámbitos como el de la poca vigencia de las garantías penales, el retraso en los procesos, y el abuso en general sobre la persona del imputado.

De los aspectos comentados en el cuerpo de este artículo, destaca por ejemplo el asunto del acceso y la inmediación en segunda instancia. El nuevo código procesal acusatorio mexicano ${ }^{36}$ ha limitado que la apelación de la sentencia definitiva procede en relación con aquellas consideraciones distintas a la valoración de la prueba siempre y cuando no comprometan el principio de inmediación. De este modo, se entiende que se limita el ámbito del recurso a temas que no supongan una revisión de los hechos fijados a partir de las pruebas desahogadas ante el tribunal oral. Asimismo, la legislación señala que la apelación de la sentencia procede por actos que impliquen una violación "grave» del debido proceso. En todo caso, lo que habrá que cuidarse en la aplicación de este precepto es que el acceso limitado a la apelación no se interprete de manera demasiado estricta, de modo que resulte en una violación del derecho de acceso a la segunda instancia.

\footnotetext{
${ }^{36}$ Código Nacional de Procedimientos Penales, artículo 468, fracción II.
} 
Otro asunto que amerita atención es el relativo a los efectos extraprocesales de la presunción de inocencia, que ameritan mayor atención en el contexto mexicano. Se ha visto en el artículo que el derecho puede verse vulnerado cuando cualquier funcionario del Estado anticipa una manifestación sobre la culpabilidad de una persona imputada, antes de que su responsabilidad se declare en sentencia. Esto debe atenderse, pues en nuestro contexto es común que las autoridades de seguridad pública y procuración de justicia presenten públicamente a indiciados, a los que se identifican como responsables de delitos. Por no hablar de los juicios mediáticos, que también se hacen habituales.

\section{BIBLIOGRAFÍA}

ARANGÜEna FANEgo, Coral, «Primera aproximación al derecho a un proceso equitativo y a las exigencias contenidas en el art. 6.1 CEDH; en particular, el derecho de acceso a un tribunal», en GARCÍA Roca, Francisco Javier (Coord.), La Europa de los Derechos. El Convenio Europeo de Derechos Humanos, 2. ${ }^{\text {a }}$ ed., Centro de Estudios Políticos y Constitucionales, Madrid, 2009, págs. 259-275.

Caballero Juárez, José Antonio, El debido proceso. Una aproximación desde la jurisprudencia latinoamericana, Suprema Corte de Justicia de la Nación, Oficina en México del Alto Comisionado de las Naciones Unidas para los Derechos Humanos, México, 2014.

Casadevall, Josep, El Convenio Europeo de Derechos Humanos, el Tribunal de Estrasburgo y su Jurisprudencia, Tirant lo Blanch, Valencia, 2012.

Dolzer, Rudolf y WeTzel, Jan, «El derecho del acusado a un juicio justo según la Convención Europea de Derechos Humanos», Anuario de Derecho Constitucional Latinoamericano, tomo II, 2006, págs. 1175-1190.

JIMENA QUESADA, Luis, «El derecho a un proceso equitativo reconocido en el Convenio Europeo de Derechos Humanos y su proyección nacional: entre el tiempo para conocer Europa y el tiempo para hacer justicia conforme a los parámetros europeos», Cuadernos Constitucionales de la Cátedra Fadrique Furió Ceriol, núm. 50/51, 2005, págs. 177-191.

Loayza TAmaYo, Carolina, «El debido proceso en la jurisprudencia de la Corte Interamericana», LEX. Revista de la Facultad de Derecho y Ciencia Politica de la Universidad Alas Peruanas, vol. 10, núm. 9, 2012, págs. 83-126. 
Marabotto Lugaro, Jorge A., «Un derecho humano esencial: el acceso a la justicia», Anuario de Derecho Constitucional Latinoamericano, 2003, págs. 291-301.

Rey Martínez, Fernando, «¿Cómo Nacen los derechos? (Posibilidades y Límites de la Creación Judicial de Derechos)», en BAZÁN, Víctor (Coord.), Derecho Procesal Constitucional Americano y Europeo, Buenos Aires, Abeledo Perrot, 2010, t. II, págs. 1477-1478.

RodRÍGUEZ FERNÁNDEZ, Ricardo, Derechos fundamentales y garantías individuales en el proceso penal. Nociones básicas. Jurisprudencia esencial, Comares, Granada, 2000.

Salah Palacios, Emilio, La tutela judicial efectiva en la jurisprudencia del Tribunal Constitucional 1981-2014, Cultiva Libros, Madrid, 2015.

VV. AA., Convenio Europeo de Derechos Humanos. Comentario sistemático, 2a. ed., Civitas, Thomson Reuters, Pamplona, 2009. 